\title{
Comentário a \\ “O externalismo semiótico ativo de C. S. Peirce e a CANTORIA DE VIOLA COMO SIGNO EM AÇÃO”: EM BUSCA DE UMA ONTOLOGIA PARA O PARADIGMA 4E
}

\author{
Cesar Fernando Meurer ${ }^{1}$ \\ Nara Miranda de Figueiredo ${ }^{2}$
}

Referência do artigo comentado: ATÁ, P.; QUEIROZ, J. O externalismo semiótico ativo de C. S. Peirce e a cantoria de viola como signo em ação. Trans/Form/Açáo: revista de filosofia da Unesp, v. 44, n. 3, p. 177-204, 2021.

No artigo "O externalismo semiótico ativo de C. S. Peirce e a cantoria de viola como signo em ação”, Atã e Queiroz (2021) almejam “[...] fornecer uma ontologia semiótica para o externalismo cognitivo ativo, como desenvolvido recentemente pelo paradigma 4E.” Neste comentário, oferecemos uma caracterização sucinta do campo das abordagens ontológicas da cognição e apresentamos consideraçóes que ajudam a situar a posição de Atã e Queiroz (2021), nesse campo.

\footnotetext{
${ }_{1}^{1}$ Professor no Centro de Ciências Naturais e Humanas da Universidade Federal do ABC (UFABC), São Paulo, SP - Brasil. (D) https://orcid.org/0000-0002-9504-0325 E-mail: cesarmeurer@gmail.com 2 Centro de Lógica, Epistemologia e História da Ciência da Universidade Estadual de Campinas (UNICAMP), Campinas, SP - Brasil. (D) https://orcid.org/0000-0003-0270-7467 E-mail: naramfigueiredo@gmail.com

https://doi.org/10.1590/0101-3173.2021.v44n3.16.p205
} 
A primeira frase do artigo de Atã e Queiroz (2021), na qual eles anunciam o propósito de fornecer uma ontologia para o paradigma $4 \mathrm{E}$, tem certamente o mérito de chamar a atenção de leitores que se dedicam sistematicamente à filosofia. A hipótese de trabalho deles, "[...] que o componente explanatório que falta ao externalismo cognitivo não centrado no indivíduo é a noção pragmatista de semiose (ação de signos) de Peirce" (ATÃ; QUEIROZ, 2021, p. 181), também desperta interesse.

O presente comentário tem dois objetivos: caracterizar sucintamente o campo das abordagens ontológicas da cognição e oferecer elementos que ajudem a situar a posição de Atã e Queiroz (2021), nesse campo.

Barry Smith, professor na State University of New York at Buffalo, é um dos filósofos contemporâneos mais importantes no que tange à ontologia e à ontologia da cognição. ${ }^{3}$ Nas palavras dele, ontologia é "[...] a ciência do que é, dos tipos e estruturas de objetos, propriedades, eventos, processos e relações em cada área da realidade.”^ (SMITH, 2004, p. 155). Dessa definição geral, a qual posiciona a ontologia como um ramo da filosofia, derivamos que a ontologia da cognição é a ciência dos tipos e estruturas de objetos, propriedades, eventos, processos e relaçóes que há em uma área da realidade, a cogniç̧ão.

Nas últimas décadas, em parte devido ao surgimento e aperfeiçoamento de técnicas de neuroimagem, o interesse pela ontologia da cognição se disseminou em diversas áreas, tais como a neurologia (PRICE; FRISTON, 2005; FRISTON; PRICE, 2011; BATRANCOURT et al., 2015), a psiquiatria (BLUHM, 2017), a psicologia (POLDRACK; YARKONI, 2016; GADSBY, 2019), a neurociência cognitiva (LENARTOWICZ et al., 2010) e obviamente a filosofia (FIGDOR, 2011; FUMAGALLI, 2016; HUTTO; PEETERS; SEGUNDO-ORTIN, 2017; DEWHURST, 2021).

Uma consequência dessa disseminação é que a expressão "ontologia cognitiva" (ou sua variante "ontologia da cognição") já não guarda significado unívoco. Jansen, Kein e Slors (2017) fizeram um levantamento e constataram que a expressão vem sendo usada de três maneiras diferentes, na literatura contemporânea: (i) para referir uma nomenclatura, isto é, "[...] um conjunto de termos padronizados que pesquisadores pretendem usar de forma sistemática a

\footnotetext{
${ }^{3}$ Leitores interessados em ontologia podem se beneficiar de uma visita ao site http://ontology.buffalo. edu, mantido pelo prof. Smith <http://ontology.buffalo.edu/smith/ (conteúdo em língua inglesa).

${ }^{4} \mathrm{~A}$ tradução desta e das demais citaçōes diretas é nossa (tradução livre).
} 
fim de promover o entendimento mútuo" (JANSEN; KEIN; SLORS, 2017, p. 124); (ii) para designar um domínio, isto é, "[...] o conjunto de entidades referidas por uma teoria cognitiva" (JANSEN; KEIN; SLORS, 2017, p. 124); (iii) como um conjunto de categorias metafísicas básicas a partir das quais o domínio cognitivo pode ser demarcado e estruturado (e.g. mecanismos, processos, conceitos clínicos etc.).

Jansen, Klein e Slors (2017) também constataram que as contemporâneas abordagens ontológicas da cognição têm foco em três conjuntos interconectados de questôes: (a) questôes acerca do escopo do explanandum e dos níveis nos quais ele pode ser analisado; (b) questôes concernentes à adoção de uma perspectiva realista, ou não, em relação às categorias de certa ontologia; e (c) questóes a propósito da manutenção, ou não, de categorias psicológicas em face dos avanços das neurociências.

Essas constataçôes de Jansen, Klein e Slors (2017) podem ajudar a situar a posição de Atã e Queiroz (2021), no campo dos estudos da ontologia da cognição. Vejamos.

a) Escopo do explanandum. Atã e Queiroz (2021) são liberais: assumem que sistemas cognitivos podem ser distribuídos, isto é, que a cognição não se limita ao cérebro e nem mesmo ao corpo biológico do agente, mas inclui também artefatos e aspectos do ambiente. A cantoria de viola - concebida como algo que abrange a improvisação dos versos, a viola (instrumento), as toadas, os motes, as deixas, os repentistas, os curadores, os apologistas, a audiência etc. - é descrita como um sistema cognitivo distribuído.

Posiçôes liberais em relação ao escopo da cognição são conhecidas e já foram intensamente debatidas, na comunidade filosófica (CLARK; CHALMERS, 1998; CLARK, 2003; MENARY, 2010). Uma questão difícil, para quem é liberal, diz respeito à individuaçáo de sistemas cognitivos de modo a acomodar tanto a consciência individual quanto a cognição grupal. Uma teoria geral da individuação de sistemas cognitivos ainda não foi estabelecida (RUPERT, 2019a; 2019b).

b) Adoção ou não de uma perspectiva realista. Atã e Queiroz (2021) são peircianos: professam um credo que dificilmente pode ser caracterizado como realista. Ajuizamos isso com base em Burch (2021), que identifica quatro componentes do idealismo hegeliano em Peirce: a tese de que o mundo das aparências é constituído inteiramente de signos, a tese de que o signo é um elemento de uma relação triádica indissoluvelmente conectada, a tese de que 
o interpretante de um signo é ele mesmo um signo e a tese de que o sistema todo evolui. Em atenção a esses componentes, Burch (2021, s/p) conclui que

[...] temos em Peirce uma teoria essencialmente idealista que é semelhante ao idealismo que Hegel apresenta na Fenomenologia do Espírito. Além disso, tanto Hegel quanto Peirce fazem toda a interpretação evolucionária do faneron em evolução ser um processo que se diz lógico, a "ação" da própria lógica.

O próprio Peirce registrou certa vez que "[...] a única teoria inteligível do universo é a do idealismo objetivo.” (PEIRCE, 1891, p. 171). Por que uma ontologia idealista seria desejável para o paradigma 4E? Um ponto difícil que surge aqui é se uma ontologia idealista pode suportar uma explicação naturalizada da cogniçáo.

c) Manutenção ou não de categorias psicológicas diante de avanços nas neurociências. É importante saber se a ontologia semiótica que Atã e Queiroz (2021) recomendam ao paradigma $4 \mathrm{E}$ é de algum modo sensível ou informada por achados das neurociências. Ao nosso modo de pensar, esta pergunta é crucial: pode algum avanço nas ciências empíricas da cognição motivar uma atualização na ontologia semiótica? Se sim, qual aspecto ou elemento dessa ontologia é passível de revisão, à luz de novas evidências neurocientíficas?

Este comentário procurou caracterizar sucintamente o campo das abordagens ontológicas da cognição e oferecer elementos que ajudem a situar a posição de Atã e Queiroz, nesse campo. As perguntas que apresentamos são expressão do nosso interesse na colaboração interdisciplinar e no avanço do conhecimento. As respostas que Atã e Queiroz eventualmente apresentarem vão nos ajudar a discernir se o artigo em comento usa o termo "ontologia" para referir uma nomenclatura, um domínio de entidades ou categorias metafísicas básicas. Isso, por sua vez, vai informar mais detalhes acerca de como eles compreendem a interface do paradigma $4 \mathrm{E}$ com as ciências empíricas da cognição, especialmente as neurociências.

\section{REFERÊNCIAS}

ATÃ, P; QUEIROZ, J. O externalismo semiótico ativo de C. S. Peirce e a cantoria de viola como signo em ação. Trans/Form/Açáo: revista de filosofia da Unesp, v. 44, n. 3, p. 177-204, 2021. 
BATRANCOURT, B.; DOJAT, M.; GIBAUD, B.; KASSEL, G. A multilayer ontology of instruments for neurological, behavioral and cognitive assessments. Neuroinformatics, v. 13, n. 1, p. 93-110, 2015. https://doi.org/10.1007/s12021-014-9244-3.

BLUHM, R. The need for new ontologies in psychiatry. Philosophical Explorations, v. 20, n. 2, p. 146-159, 2017. https://doi.org/10.1080/13869795.2017.1312498.

BURCH, R. Charles Sanders Peirce. In: ZALTA, E. (ed.). The Stanford Encyclopedia of Philosophy, Spring 2021 Edition. Disponível em: https://plato.stanford.edu/archives/ spr2021/entries/peirce. Acesso em: 15 de mar. de 2021.

CLARK, A.; CHALMERS, D. The extended mind. Analysis, v. 58, n. 1, p. 07-19, 1998. https://doi.org/10.1093/analys/58.1.7.

CLARK, A. Natural-born cyborgs: minds, technologies, and the future of human intelligence. New York; Oxford: Oxford University Press, 2003.

DEWHURST, J. Folk psychological and neurocognitive ontologies. In: CALZAVARINI, F.; VIOLA, M. (ed.). Neural mechanisms: new challenges in the philosophy of neuroscience. Cham: Springer, 2021. p. 311-334. https://doi.org/10.1007/978-3-03054092-0_14.

FIGDOR, C. Semantics and metaphysics in informatics: toward an ontology of tasks. Topics in Cognitive Science, v. 3, n. 2, p. 222-226, 2011. https://doi.org/10.1111/ j.1756-8765.2011.01133.x.

FRISTON, K. J.; PRICE, C. J. Modules and brain mapping. Cognitive

Neuropsychology, v. 28, n. 3-4, p. 241-250, 2011. https://doi.org/10.1080/02643294.2 011.558835 .

FUMAGALLI, R. Choice models and realistic ontologies: three challenges to neuropsychological modellers. European Journal for Philosophy of Science, v. 6, n. 1, p. 145-164, 2016. https://doi.org/10.1007/s13194-015-0134-9.

GADSBY, S. Body representations and cognitive ontology: drawing the boundaries of the body image. Consciousness and Cognition, v. 74, p. 102772, 2019. https://doi. org/10.1016/j.concog.2019.102772.

HUTTO, D; PEETERS, A; SEGUNDO-ORTIN, M. Cognitive ontology in flux: the possibility of protean brains. Philosophical Explorations, v. 20, n. 2, p. 209-223, 2017. https://doi.org/10.1080/13869795.2017.1312502.

JANSEN, A.; KLEIN, C.; SLORS, M. What is a cognitive ontology, anyway?

Philosophical Explorations, v. 20, n. 2, p. 123-128, 2017. https://doi.org/10.1080/138 69795.2017.1312496.

LENARTOWICZ, A.; KALAR, D. J.; CONGDON, E.; POLDRACK, R. A. Towards an ontology of cognitive control. Topics in Cognitive Science, v. 2, n. 4, p. 678-692, 2010. https://doi.org/10.1111/j.1756-8765.2010.01100.x. 
MENARY, R. (ed.). The extended mind. Cambridge, MA: The MIT Press, 2010. https://doi.org/10.7551/mitpress/9780262014038.001.0001.

PEIRCE, C. S. The architecture of theories. The Monist, v. 1, n. 2, p. 161-176, 1891. https://doi.org/10.5840/monist18911211.

POLDRACK, R.; YARKONI, T. From brain maps to cognitive ontologies: informatics and the search for mental structure. Annual Review of Psychology, v. 67, n. 1, p. 587612, 2016. https://doi.org/10.1146/annurev-psych-122414-033729.

PRICE, C. J.; FRISTON, K. J. Functional ontologies for cognition: the systematic definition of structure and function. Cognitive Neuropsychology, v. 22, n. 3, p. $262-$ 275, 2005. https://doi.org/10.1080/02643290442000095.

RUPERT, R. Group minds and natural kinds. Avant: Trends in Interdisciplinary Studies, v. 10, n. 3, p. 01-28, 2019a. http://dx.doi.org/10.26913/avant.2019.03.08.

RUPERT, R. What is a cognitive system? In defense of the conditional probability of cocontribution account. Cognitive Semantics, v. 5, n. 2, p. 175-200, 2019b. https://doi. org/10.1163/23526416-00502001.

SMITH, B. Ontology. In: FLORIDI, L. (ed.). The Blackwell guide to the philosophy of computing and information. Malden, MA; Oxford, UK: Blackwell, 2004. p. 155166. https://doi.org/10.1002/9780470757017.ch11.

Recebido: 28/3/2021

Aceito: $03 / 4 / 2021$ 